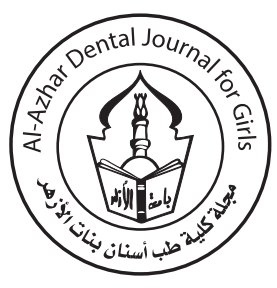

\title{
Shear Bond Strength of Low Shrinkage Resin Composite to Resin Modified and Nano-Filled Glass Ionomer Cements
}

\author{
Wael E. Jamil ${ }^{(1)}$ and Sahar M. Elmarsafy ${ }^{(2)}$
}

Codex : 07/1801

azhardentj@azhar.edu.eg

http://adjg.journals.ekb.eg

\section{KEYWORDS}

Shear bond strength,

Low shrinkage composite resin, RMGI, Nanofilled GI,

Glass ionomer surface finishing

\begin{abstract}
Objective: This study was designed to assess the shear bond strength between low shrinkage composite to resin-modified and nanofilled glass ionomer cements using different rotary instruments to finish the surface of glass ionomer cements. Materials and Methods: Sixty standardized cylindrical glass ionomer specimens were prepared using a split Teflon mold. They were divided into two main groups (30 specimens each), according to the type of the glass ionomer used (Vitremer RMGI and N100 nanofilled GI). Each group was further subdivided into three subgroups (10 specimens each) according to their surface finish, either cured against mylar strip, finishing the surface with carbide bur and diamond stone. Then they were bonded to low shrinkage resin composite (Feltic P90). The specimens were subjected to shear bond strength testing. The data were collected, tabulated and statistically analyzed. Results: Both carbide bur and diamond stone had statistically significant higher shear bond strength compared to specimens cured against the mylar strip. Statistically significant higher shear bond strength values were recorded with Vitremer RMGI finished with carbide and N100 nanofilled GI finished with diamond stone. Conclusions: RMGI finished with carbide bur and nanofilled GI finished with diamond stone as a base under low shrinkage composite provided the highest shear bond strength results.
\end{abstract}

\section{INTRODUCTION}

Resin composite materials have improved greatly since their introduction more than 40 years ago. Although composites are now the material of choice for most restorations, their polymerization shrinkage remains a major problem. The contraction stresses associated with shrinkage can cause debonding at the composite/tooth interface and can contribute to post-operative sensitivity, enamel fracture, recurrent caries, marginal staining and eventual failure of the restoration ${ }^{(1)}$.

1. Assistant Professor of Operative Dentistry, Faculty of Dental Medicine for Girls, Al-Azhar University.

2. Assistant Professor of Operative Dentistry, Faculty of Dental Medicine for Girls, Al-Azhar University \& Faculty of DentistryUmm Al-Qura University, Kingdom Saudi Arabia. 
The sandwich or laminate technique, as developed by McLean et al., employed the use of glass ionomer as a base beneath composite restorations providing effective method to reduce microleakage at restoration margins ${ }^{(2,3)}$.

In the sandwich technique, the doubtful bond between the composite resin and glass-ionomer cement is one of the most important factors which lead to the failure of restoration ${ }^{(4)}$. The proper bond between glass ionomer cement and resin composite is necessary for successful restoration. This method is mainly applied to benefit from both the physical and aesthetic properties of these materials ${ }^{(5)}$. Some studies have shown that the use of resin-modified glass ionomer (RMGI) in the sandwich technique results in a significantly higher bond strength to composite resin compared with the use of conventional GI ${ }^{(6)}$.

To date, the main strategy to reduce shrinkage in composites has focused on increasing the filler load, thereby reducing the proportion of the methacrylate resin. However, the shrinkage intrinsic to the methacrylate resin still remains a challenge. Therefore, exchanging the resin seems the most promising pathway to solve the shrinkage problem. This has led to the advent of ring opening polymerization of silorane molecules. This new silorane based composites, showed volumetric shrinkage of $<1 \%$ and hence reduced the polymerization stress and its ill effects ${ }^{(7)}$.

As silorane composites are a new introduction into dentistry, the possibility of bonding them to different glass ionomer cements needs to be studied $^{(8)}$. Therefore The null hypothesis tested in this study was the shear bond strength between silorane-based composite (Filtek P9; 3M ESPE, St Paul, MN, USA) to resin-modified glass ionomer cement (Vitrebond; 3M ESPE) and nanofilled glass ionomer cement (Ketac N100; 3M ESPE) would not be affected with using different rotary instruments to finish the surface of glass ionomer.

\section{MATERIALS AND METHODS}

A total of 60 glass ionomer specimens were prepared and classified into two main groups of 30 specimens each according to the type of glass ionomer used either $\mathbf{A}_{\mathbf{1}}$ for Vitremer and $\mathbf{A}_{\mathbf{2}}$ for ketac N100 light curing resin modified nanoionomer ${ }^{(9)}$. Each group further subdivided into three sub groups (10 specimens each) according to type of rotary instrument used for its surface finishing.

\section{Sample preparation}

Cylindrical glass ionomer specimens were prepared using a split Teflon mold. The Teflon mold has a central hole $6 \mathrm{~mm}$ in diameter and 3 mm depth, surrounded by a metallic ring. In $\mathbf{A}_{1}$ Group, Vitremer light cure resin modified glass ionomer liner/base: one scoop of powder and one drop of liquid were dispensed onto a paper pad and mixed rapidly using an agate spatula for 10 15 sec. according to manufacturer's instructions. The mixed cement was carried to the mold using a cement-carrying instrument and condensed using a cylindrical condenser into two increments of $1.5 \mathrm{~mm}$ thickness each and light cured for $30 \mathrm{sec}$. While in $\mathbf{A}_{2}$ Group, Ketac N100 light curing nanofilled GI: equal amounts of pastes in a clicker system were dispensed onto a paper pad. The pastes were mixed for $20 \mathrm{sec}$. according to manufacturer's instructions to obtain a uniform colored paste. The mixed cement was carried to the mold using a plastic instrument and condensed with a cylindrical condenser into two increments and each was light cured for 20 $\mathrm{sec}^{(8)}$. The metallic ring surrounding the mold was removed; splitting the mold into two halves and the (3x6) specimens were easily removed.

Each group of specimens were subjected to different surface treatments according to its subgrouping: $\mathbf{B}_{\mathbf{0}}$ with no rotary surface instrumentation (control), $\mathbf{B}_{\mathbf{1}}$ with surface instrumented by 5 strokes of $200 \mathrm{gm}$ constant pressure with a high speed carbide fissure bur (CFB) (meisinger size: 012) and $\mathbf{B}_{2}$ with surface instrumented by 5 strokes of $200 \mathrm{gm}$ constant pressure with a high speed diamond abrasive tapered stone (DAS) (meisinger size: 012). 
The final GI/Composite specimens were performed within a second Teflon mold, which prepared with central hole of $6 \mathrm{~mm}$ diameter and $6 \mathrm{~mm}$ depth, can be split in two halves and surrounded by a metallic ring.

After placing the glass ionomer specimen in the Teflon mold, all the specimens were restored using the P90 system adhesive (3M ESPE, St Paul, MN, USA) and Filtek P90 low-shrink posterior restorative microhybrid composite resin ${ }^{(10)}$. A self-etch primer was applied to the glass ionomer cement surface using an applicator brush and rubbed for $15 \mathrm{sec}$; this was followed by gentle air dispersion to form an even film and light cured for $10 \mathrm{sec}$. The adhesive was applied using an applicator tip followed by gentle air dispersion to spread to an even film and light cured for $10 \mathrm{sec}$. After adhesive application, samples were restored with Filtek P90 low-shrink posterior restorative microhybrid composite (A2 shade). The material was placed in two increments of $1.5 \mathrm{~mm}$ each with adequate compaction and each increment was light cured for $20 \mathrm{sec}$. Finally, the metallic ring was removed splitting the Teflon mold into two halves and the glass ionomer/composite specimen was easily removed..

All specimens were polymerized under plastic matrix strips in split Teflon mold and light cured with Prolux 570 light curing unit (Ping lim Enterprise Co., Taiwan): A LED curing unit with light wave length (400- $510 \mathrm{~nm})$. The intensity of the curing light was regularly monitored using a radiometer (curing radiometer Model 100, Demetron Research Corp, Danbury, USA). After curing, specimens were stored for $24 \mathrm{~h}$ at $37^{\circ} \mathrm{C}$ and $100 \%$ relative humidity before SBS testing. The specifications of the products are listed in Table 1 .

Table (1): Materials*, chemical composition and type:

\begin{tabular}{|c|c|c|}
\hline Material* & Chemical composition/ Mean particle size & Type \\
\hline $\begin{array}{c}\text { Filtek P90 } \\
\text { Composite resin }\end{array}$ & $\begin{array}{c}\text { Silorane resin (siloxane }+ \text { oxirane) } 23 \% \text {, filler (quartz and yttrium } \\
\text { fluoride) } 76 \% \text {, initiating system (camphorquinone, iodonium salt } \\
\text { and electron donors) } 0.9 \% \text { and stabilizer } \mathbf{0 . 1 3 \%} \text {, and pigments, } \\
\mathbf{0 . 0 0 5 \% . 0 . 4 - 1 . 7} \boldsymbol{~ m}^{\mathbf{9})}\end{array}$ & \multirow{3}{*}{$\begin{array}{l}\text { Microhybrid resin } \\
\text { composite }\end{array}$} \\
\hline P90 system adhesive self etch prime & $\begin{array}{c}\text { Phosphorylated methacrylates, Vitrebond copolymer, bisphenol } \\
\text { A-glycidyl methacrylate, HEMA, water, ethanol, silane-treated } \\
\text { silica filler, initiators, stabilizers }\end{array}$ & \\
\hline P90 system adhesive bond & $\begin{array}{c}\text { Hydrophobic dimethacrylate, phosphorylated methacrylate, } \\
\text { tetraethyleneglycol dimethacrylate, silane-treated silica filler, } \\
\text { initiators, and stabilizers }\end{array}$ & \\
\hline $\begin{array}{l}\text { Vitrebond light cure glass ionomer } \\
\text { liner/base powder }\end{array}$ & Ion leachable flouro-aluminosilicate glass powder. $\mathbf{0 . 3} \boldsymbol{\mu} \mathbf{m}^{(\mathbf{1 0 )}}$ & \multirow{2}{*}{ RMGI } \\
\hline $\begin{array}{l}\text { Vitrebond light curing glass ionomer } \\
\text { liner/base liquid }\end{array}$ & $\begin{array}{l}\text { Modified ion leachable polyacrylic acid with pendant methacrylate } \\
\text { groups, HEMA, water and photoinitiators }\end{array}$ & \\
\hline $\begin{array}{l}\text { Ketac N100 light curing nano- } \\
\text { ionomer restorative pastes }\end{array}$ & $\begin{array}{l}\text { Aqueous paste (acidic polyalkenoic acid, reactive resins and nano- } \\
\text { fillers) and nonaqueous paste (FAS glass, reactive resins, and } \\
\text { nano-fillers). The filler loading is approximately } 69 \% \text { by weight, } \\
27 \% \text { FAS glass (acid and free radical reactive) } 42 \% \text { methacrylate } \\
\text { functionalized nano-fillers chemically derived from both silica and } \\
\text { zirconia (acid and free radically reactive). Nano-fillers are further } \\
\text { surface modified with methacrylate silane coupling agents. } \\
\mathbf{1} \boldsymbol{\mu} \mathbf{m} \text { (cluster), } \mathbf{5 - 2 5} \mathbf{~ n m} \text { (nanofiller), } \mathbf{3 . 0} \boldsymbol{\mu} \mathbf{m} \text { (glass) }\end{array}$ & $\begin{array}{l}\text { Nano-ionomer } \\
\text { glass ionomer }\end{array}$ \\
\hline
\end{tabular}

*: All products supplied by $3 M$ ESPE, St, Pual, MN, USA. 
The shear bond strength was evaluated by the universal testing machine (Lloyd testing machine, England) using a especially constructed metallic attachment with two sliding parts with a hole of $3 \mathrm{~mm}$ passing through the two sliding parts. Each sliding part of the metallic attachment will hold only one material in order to determine the shear bond strength between resin composite and the GIC at a crosshead speed of $0.5 \mathrm{~mm} / \mathrm{min}$ and a load cell of $50 \mathrm{~kg}$. The bond strength value was recorded and converted to Mega Pascals (MPa) according to the following equation:

SBS in $\mathrm{MPa}=(\mathrm{L} / \mathrm{a}) \times 0.0981\left(1 \mathrm{Kg} / \mathrm{cm}^{2}=0.0981 \mathrm{MPa}\right)$

Where: $\mathrm{L}=$ breaking load in $\mathrm{Kg}$

$\mathrm{a}=$ area of composite/ dentin surface in $\mathrm{cm}^{2}$

The obtained data were statistically analyzed using Aasistat 7.6 statistics software for Windows (Campina Grande, Paraiba state, Brazil). One way ANOVA followed by pair-wise Duncn post-hoc tests were performed to detect significance between subgroups. Student t-test was performed to detect significance at $\mathrm{P}$ values $\leq 0.05$.

\section{RESULTS}

In comparison between the two types of glass ionomers regardless to surface treatments; totally it was found that vitremer recorded statistically non-significant $(\mathrm{P}>0.05)$ higher shear bond strength mean value $(24.4 \pm 4.9 \mathrm{MPa})$ than $N 100(23.74 \pm 3.8$ $\mathrm{MPa})$. In comparison between different surface treatments regardless to glass ionomer type; totally it was found that Carbide bur recorded the highest statistically significant $(\mathrm{P}<0.05)$ shear bond strength mean value $(27.175 \pm 4.665 \mathrm{MPa})$ followed by Diamond stone $(25.515 \pm 3.975 \mathrm{MPa})$ while control showed the lowest statistically significant shear bond strength mean value (19.57 $\pm 0.35 \mathrm{MPa})$. Table (2)
Table (2) Comparison between total shear bond strength results (Mean values \pm SDs) for different glass ionomers and surface treatments

\begin{tabular}{|c|c|c|c|}
\hline & Variable & Mean \pm SD & P value \\
\hline \multirow{2}{*}{$\begin{array}{c}\text { Glass } \\
\text { Gonomer }(A)\end{array}$} & Vitremer $\left(\boldsymbol{A}_{1}\right)$ & $24.4 \pm 4.9$ & \multirow{2}{*}{$0.5434 \mathrm{~ns}$} \\
\cline { 2 - 4 } & Ketac N100 $\left(\boldsymbol{A}_{2}\right)$ & $23.74 \pm 3.8$ & \\
\hline \multirow{3}{*}{$\begin{array}{c}\text { Surface } \\
\text { treatment }(\boldsymbol{B})\end{array}$} & $\operatorname{Control}\left(\boldsymbol{B}_{0}\right)$ & $19.57 \pm 0.35^{\mathrm{b}}$ & \multirow{2}{*}{$<0.001^{*}$} \\
\cline { 2 - 4 } & Carbide bur $\left(\boldsymbol{B}_{1}\right)$ & $27.175 \pm 4.665^{\mathrm{a}}$ & \\
\cline { 2 - 3 } & Diamond stone $\left(\boldsymbol{B}_{2}\right)$ & $25.515 \pm 3.975^{\mathrm{a}}$ & \\
\hline
\end{tabular}

* Different letter in the same column indicating statistically significant difference $(p<0.05)$.

*; significant $(P \leq 0.05)$ ns; non-significant $(P>0.05)$

Meanwhile in the interaction between variables it was found that with vitremer, the Carbide bur recorded the highest statistically significant shear bond strength mean value $(31.84 \pm 4.9 \mathrm{MPa})$ followed by Diamond stone $(21.54 \pm 3.1 \mathrm{MPa})$ while control showed the lowest statistically significant shear bond strength mean value $(19.92 \pm 3.9 \mathrm{MPa})$. While with N100 it was found that Diamond stone recorded the highest statistically significant shear bond strength mean value $(29.49 \pm 4.5 \mathrm{MPa})$ followed by Carbide bur $(22.51 \pm 5.3 \mathrm{MPa})$ while control showed the lowest statistically significant shear bond strength mean value $(19.22 \pm 4.3 \mathrm{MPa})$. Pair-wise Duncan post-hoc test showed that there was no significant difference between control and diamond stone with vitremer and no significant difference between control and carbide bur with N100 ( $>$ > 0.05).. Table (3)

Table (3) Comparison between the shear bond strength results (Mean values $\pm S D s$ ) of interactive variables

\begin{tabular}{|c|c|c|c|c|}
\hline Variable & $\begin{array}{c}\text { Control } \\
\left(\mathrm{B}_{0}\right)\end{array}$ & $\begin{array}{c}\text { Carbide bur } \\
\left(\mathrm{B}_{1}\right)\end{array}$ & $\begin{array}{c}\text { Diamond stone } \\
\left(\mathrm{B}_{2}\right)\end{array}$ & P- value \\
\hline Vitremer $\left(\mathrm{A}_{1}\right)$ & $19.92 \pm 3.9^{\mathrm{b}}$ & $31.84 \pm 4.9^{\mathrm{a}}$ & $21.54 \pm 3.1^{\mathrm{b}}$ & $<0.001^{*}$ \\
\hline Ketac N100 $\left(\mathrm{A}_{2}\right)$ & $19.22 \pm 4.3^{\mathrm{b}}$ & $22.51 \pm 5.3^{\mathrm{b}}$ & $29.49 \pm 4.5^{\mathrm{a}}$ & $0.0042^{*}$ \\
\hline P- value & $0.7595 \mathrm{~ns}$ & $0.0093^{*}$ & $0.0022^{*}$ & \\
\hline
\end{tabular}

Different letter in the same column indicating statistically significant difference $(p<0.05)$.

*; significant $(P \leq 0 . .05)$ ns; non-significant $(P>0.05)$ 


\section{DISCUSSION}

Proper bond strength between resin composite and glass ionomer cement is necessary for the success of sandwich technique.. Applying self-etch adhesive over glass ionomer creates a stronger bond of composite resin to glass ionomer ${ }^{(11)}$. The bond strength between these materials is influenced by four factors: 1) the tensile strength of GIC, which is mostly dependent on the powder/liquid ratio; 2) the viscosity of the bonding agent and its ability to wet the GIC's surface; 3) the volumetric change in the composite resin during polymerization and; 4) the difficulties in packing and adaptation of the composite resin to the GIC without incorporation of voids ${ }^{(12)}$.

Silorane adhesive system is considered a mild self-etching adhesive due to its high $\mathrm{pH}$ value (2.7). It can create mechanical interlocking between the bonding agent and the porosity caused through mildly etching of the RMGI surface ${ }^{(13)}$.

Recent study reported that the mild self-etch bonding provided higher shear bond strength ${ }^{(14)}$. This might be due to the lower acidity of self-etch adhesive which causes superficial dissolution of glass ionomer and consequently improves the bond between composite resin and glass ionomer ${ }^{(15)}$. According to organic chemistry, when a weak acid invades something, it induces a minimum excitation in the ions, and hence the salt crumps formation will be minimal ${ }^{(16)}$. Cations such as $\mathrm{Ca} 2+$ and $\mathrm{Na}+$ that are not excited and are present in large amounts for effective interaction, especially in a conductive reaction medium like glass ionomer cements, instigate strong ionic reaction with the bonding agents ${ }^{(17)}$.

Moreover, self-etch adhesive has a lower viscosity compared with the total-etch adhesive ${ }^{(18,19)}$. In a research, Mount found that bonding with a lower viscosity caused low contact angle on the surface; thus, it improved the wetability and strengthened the bonding of resin composite and glass ionomer ${ }^{(20)}$. Previous studies on self-etch adhesives showed that this system bonds with the calcium in the structure of the teeth; therefore, it can possibly bond with the calcium in the structure of GI and create a higher shear bond strength ${ }^{(21,22)}$.

The technique of a glass-ionomer sample preparation can affect the bond strength results. In this study, the surface of RMGI was cured against celluloid mylar matrix. The smooth surface produced resulted in lower shear bond strength due to production of smooth and glazed cement surface rich of weak resin matrix and it may contain bubbles $^{(2)}$. Comparing between carbide bur and diamond stone, Jung $\mathrm{M}$, reported that finishing diamonds were best suited for gross removal and contouring due to their high cutting efficiency, while carbide finishing burs would be best suited for smoothing and finishing, as result of their low cutting efficiency ${ }^{(23)}$.

According to the type of glass ionomer used, vitremer produced higher total shear bond strength values than ketac N100. That was in accordance with a study reported that the increased SBS of resin composite to Vitrebond could be due to unpolymerized HEMA on the surface of Vitrebond after curing, which may penetrate and facilitate wetting of the bonding agent and composite resin during bonding. They also suggested that the availability of residual unreacted methacrylate groups on the polyacid chain within the polymerized, light-cured glass ionomer cement may lead to formation of strong covalent chemical bonds to the resin bonding agent ${ }^{(24)}$.

Ketac N100, represents a blend of fluoraluminosilicate technology (40\%) and nanotechnology (60\%), including silica cluster fillers, nanoagglomerated silica fillers. The incorporation of nanofillers in restorative materials improves the abrasive resistance because it promotes a higher filler loading with smaller particle size and provides a reduction in the interparticle spacing, which effectively protects the softer matrix, reduces the incidence of filler exfoliation, and enhances the overall resistance 
of the material to abrasion ${ }^{(9)}$. Also A nanocluster filler particle consists of loosely bound agglomerates of nano-sized filler particles. During polishing, only the nano-sized filler particles worn away whereas nanocluster are not "plucked out" from the resin matrix. Eventually, the surface has smaller defects and better polish retention and this explains the higher shear bond strength values of nanofilled ketac N100 with diamond stone abrasion ${ }^{(25,26)}$.

On the other hand, the results of the present study was supported by a study which found that the larger and irregular filler particles present in Vitremer made it easier to "pluck out" a whole filler particle from the resin matrix, which could act as an additional abrasive agent once it has detached from the surface. In addition to the filler size, the hydrophilic property of the Vitremer polymer matrix and the insufficient coherent entanglement between the ionic cross-linked polyalkenoate network and the polymeric chains could have provided a greater chemical and mechanical superficial dissolution than was associated with Ketac N100 ${ }^{(27)}$. Consequently, the null hypothesis tested, which states that the shear bond strength between silorane-based composite to resin-modified glass ionomer cement and nanofilled glass ionomer cement would not be affected with using different rotary instruments to finish the surface of glass ionomer was rejected.

\section{CONCLUSIONS}

Under the limitations of this in vitro study, it can be concluded that using RMGI finished with carbide bur or nanofilled GI cement finished with diamond stone as a base under low shrinkage composite provided the highest shear bond strength results.

\section{REFERENCES}

1. Yamazaki PCV, Bedran-Russo AKB, Pereira PNR, Swift Jr. EJ. Microleakage evaluation of a new low-shrinkage composite restorative material. Oper Dent. 2006; 31:670-6.

2. Farah CS, Orton VG, Collard SM. Shear bond strength of chemical and light cured glass ionomer cements bonded to resin composites. Aust Dent J. 1998; 43:81-6.
3. Goldman M. Polymerization shrinkage of resin-based restorative materials. Aust Dent J. 1983; 28: 156- 61.

4. Sharafeddin F, Choobineh M. Assessment of the Shear Bond Strength between Nanofilled Composite Bonded to Glass-ionomer Cement Using Self-etch Adhesive with Different $\mathrm{pHs}$ and Total-Etch Adhesive. J Dent Shiraz Univ Med Sci. 2016; 17: 1-6.

5. Koubi S, Raskin A, Dejou J, About I, Tassery H, Camps J, Proust JP. Effect of dual cure composite as dentin substitute on the marginal integrity of Class II opensandwich restorations. Oper Dent. 2010; 35: 165-71.

6. Li J, Liu Y, Liu Y, Söremark R, Sundström F. Flexure strength of resin-modified glass ionomer cements and their bond strength to dental composites. Acta Odontol Scand. 1996; 54: 55-8.

7. Weinmann $\mathrm{W}$, Thalacker C, Guggenberger R. Siloranes in dental composites. Dent Mater. 2005; 21: 68-74.

8. Babannavar R and Shenoy A. Evaluation of shear bond strength of silorane resin to conventional, resin-modified glass ionomers and nano-ionomer cements. J Investig Clini Dent. 2014; 5: 295-300.

9. Carvalho FG, Sampaio CS, Fucio SB, Carlo HL, CorrerSobrinho L, Puppin-Rontani RM. Effect of chemical and mechanical degradation on surface roughness of three glass ionomers and a nanofilled resin composite. Oper Dent. 2012; 37: 509-17.

10. Lien W, Kraig S. Vandewalle KS. Physical properties of a new silorane-based restorative system.. Dent mater. 2010; 26: $337-44$.

11. Gopikrishna V, Abarajithan M, Krithikadatta J, Kandaswamy D. Shear bond strength evaluation of resin composite bonded to GIC using three different adhesives. Oper Dent. 2009; 34: 467-71.

12. Gupta R, and Mahajan S. Shear Bond Strength Evaluation of Resin Composite Bonded to GIC Using Different Adhesives. J Clin Diagn Res. 2015; 9: 27-9.

13. Santos MJ, Podorieszach A, Rizkalla AS, Santos GC Jr. Microleakage and microtensile bond strength of silorane based and dimethacrylate-based restorative systems. Compend Contin Educ Dent. 2013; 34: 19-24.

14. Kandaswamy D, Rajan KJ, Venkateshbabu N, Porkodi I. Shear bond strength evaluation of resin composite bonded to glass-ionomer cement using self-etching bonding agents with different $\mathrm{pH}$ : In vitro study. J Conserv Dent. 2012; 15: 27-31. 
15. Hinoura K, Suzuki H, Onose H. Factors influencing bond strengths between unetched glass ionomers and resins. Oper Dent. 1991; 6: 90-5.

16. Sharafeddin F, Moradian M, Motamedi M.. Evaluation of the Shear Bond Strength of Methacrylates and Silorane based Composite resin Bonded to Resin modified Glassionomer containing Micro and Nano-hydroxyapatide.. J Dent Shiraz Univ Med Sci. 2016; 17: 142-8.

17. Coutinho E, Van Landuyt K, De Munck J, Poitevin A, Yoshida Y, Inoue S, et al. Development of a self-etch adhesive for resin-modified glass ionomers. J Dent Res. 2006; 85: 349-53.

18. Sharafeddin F, Zare S, Javnmardi Z. Effect of Home Bleaching on Microleakage of Fiber-reinforced and Particle- filled Composite Resins. J Dent Res Dent Clin Dent Prospects. 2013; 7: 211-7.

19. Kasraie S, Shokripour M, Safari M. Evaluation of microshear bond strength of resin modified glass-ionomer to composite resins using various bonding systems. J Conserv Dent. 2013; 16: 550-4.

20. Mount GJ. The wettability of bonding resins used in the composite resin/glass ionomer sandwich technique'. Aust Dent J. 1989; 34: 32-5.
21. Antonson SA, Yazici AR, Kilinc E, Antonson DE, Hardigan PC. Comparison of different finishing/polishing systems on surface roughness and gloss of resin composites. J Dent. 2011; 39: 9-17.

22. Jung M. Surface roughness and cutting efficiency of composite finishing instruments. Oper Dent. 1997; 22: 98-104.

23. Zhang Y, Burrow MF, Palamara JE, Thomas CD. Bonding to glass ionomer cements using resin-based adhesives. Oper Dent. 2011; 36: 618-25.

24. Kerby RE, Knobloch L. The relative shear bond strength of visible light curing and chemically curing glass ionomer cement to composite resin. Quintessence Int 1992; 23: 641-4.

25. Attar N. The effect of finishing and polishing procedures on the surface roughness of composite resin materials. J Contemp Dent Pract 2007; 8: 27-35.

26. Yadav RD, Raisingani D, Jindal D, Mathur R..A comparative analysis of different finishing and polishing devices on nanofilled, microfilled, and hybrid composite: a scanning electron microscopy and profilometric study. Int J Clin Pediatr Dent. 2016; 9: 201-8.

27. Peutzfeldt A, García-Godoy F, Asmussen E. Surface hardness and wear of glass ionomers and compomers. Am J Dent. 1997; 10: 15-7. 